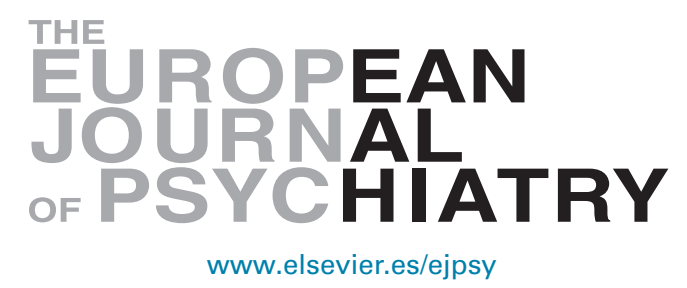

\title{
Depression and variables associated with quality of life in people over 65 in Spain and Europe. Data from SHARE 2013
}

\author{
C. Portellano-Ortiz ${ }^{a, *}$, J. Garre-Olmo ${ }^{b, c}$, L. Calvó-Perxas ${ }^{b}$, J.L. Conde-Sala ${ }^{a}$ \\ a Faculty of Psychology, University of Barcelona, Barcelona, Spain \\ ${ }^{\mathrm{b}}$ Girona Biomedical Research Institute (IDIBGI), Research Unit, Institut d'Assistència Sanitària, Salt, Spain \\ c Department of Medical Sciences, University of Girona, Spain
}

Received 29 May 2017; accepted 23 November 2017

\section{KEYWORDS \\ Aging; \\ Quality of life; \\ SHARE; \\ CASP-12; \\ EURO-D}

\begin{abstract}
Background and objectives: The perception of quality of life (QoL) in people over 65 years of age can be affected by individual clinical and sociodemographic characteristics, and also by the nature of the welfare models in place in particular countries. The objective of this study was to compare the association between clinical/sociodemographic variables and QoL in people $\geq 65$ in samples from Spain and from Central-Northern European countries, using data from the SHARE (Survey of Health, Ageing and Retirement in Europe) study.

Methods: Data from 22,189 participants in Wave 5 (2013) of the SHARE study were obtained. Instruments: CASP-12 (quality of life) and EURO-D (depression). Statistical analysis: Bivariate and multiple linear regression and correlations.

Results: In the regression analysis, the variables most closely associated with a lower QoL (CASP-12) in both groups (Spain, $r^{2}=0.586$ and Central-Northern Europe, $\left(r^{2}=0.453\right)$ were high depression ( $\beta=0.444$ vs. 0.361$)$, poor physical health, economic difficulties, and deficits in activities of daily living (ADL); low level of education was relevant only in the Spanish sample. The mean QoL score in Spain was lower than in the other countries (34.8 \pm 6.8 vs. $38.5 \pm 5.8$, $p<0.001 ; d=0.58)$ and depression was more frequent $(34.9 \%$ vs $27.4 \%, p<0.001 ; V=0.06)$.

Conclusions: In all countries, low QoL was associated with high rates of depression and poor physical health. The Spanish sample had lower QoL than their Central-Northern European counterparts. A high rate of depression was the most relevant differential variable.

๑ 2017 Asociación Universitaria de Zaragoza para el Progreso de la Psiquiatría y la Salud Mental. Published by Elsevier España, S.L.U. All rights reserved.
\end{abstract}

* Corresponding author.

E-mail address: cristina. portellano@ub.edu (C. Portellano-Ortiz).

0213-6163/@ 2017 Asociación Universitaria de Zaragoza para el Progreso de la Psiquiatría y la Salud Mental. Published by Elsevier España, S.L.U. All rights reserved.

Please cite this article in press as: Portellano-Ortiz C, et al. Depression and variables associated with quality of life in people over 65 in Spain and Europe. Data from SHARE 2013. Eur. J. Psychiat. 2017. https://doi.org/10.1016/j.ejpsy.2017.11.002 


\section{Introduction}

As the population ages due to the increase in life expectancy and the reduction in birth rates, ${ }^{1}$ the health status of the elderly and their quality of life (QoL) have become issues of particular importance. ${ }^{2}$

In old age, many aspects of health or everyday living take on a special relevance, often for the first time in an individual's life: for example, physical health, functional status, ${ }^{3-6}$ relationships and social support, ${ }^{7-10}$ adequate financial resources, ${ }^{11-13}$ satisfaction with life, ${ }^{14-16}$ presence of depression, ${ }^{17-23}$ age, gender and marital status. ${ }^{13,24-33}$ The present study sets out to analyze the aspects specifically associated with QoL in older adults.

Generally speaking, characteristics of aging such as poorer physical health and greater difficulties in activities of daily living $(A D L)^{3-5}$ tend to have a negative effect on levels of well-being. ${ }^{24}$ Nevertheless, several authors argue that a healthy lifestyle including regular physical exercise and engagement in leisure activities can raise levels of QoL in older adults, while at the same time attenuating possible depressive symptoms. ${ }^{17,19-21}$ For its part, social support can also mitigate depressive symptoms by favoring increased QoL, ${ }^{9}$ which is associated with higher life satisfaction. ${ }^{14,16}$

As regards gender, several studies have found that women generally report lower QoL than men. ${ }^{3,26-31}$ Gender also affects the experience of widowhood, suggesting that there are complex couple dynamics that mediate the relationship between marital status and QoL. ${ }^{32,33}$

It has been proposed that socioeconomic status does not affect QoL in the elderly, but that higher educational level is associated with greater well-being. ${ }^{34}$ However, other studies maintain that both aspects influence the perception of QoL, ${ }^{11-13}$ while still others propose a relation between QoL and employment status. ${ }^{35,36}$

Comparing levels of QoL in different geographical settings, some research suggests that the variations between countries depend more on the degree of cohesion of a particular society than on its level of wealth and resources. ${ }^{37}$ Other studies, however, claim the opposite, suggesting that QoL in older adults is higher in states with more generous welfare systems. ${ }^{38,39}$

The countries of Eastern and Southern Europe are characterized by greater limitations in social benefits, greater economic inequalities and a lower QoL than in Central and Northern Europe countries. ${ }^{40}$ As QoL is similar in Spain and in the other countries of Southern and Eastern Europe, ${ }^{39}$ we thought it would be interesting to contrast the characteristics of the Spanish sample with samples from Central and Northern European countries and to try to identify the variables that were most responsible for the marked differences between these populations.

Thus, the objective of this study was to analyze and compare the relationship of clinical and sociodemographic variables with QoL in the over-65s in Spain and in the Central and Northern European countries participating in the SHARE study.
Method

\section{Design and study population}

The data used were taken from Wave 5 of the Survey of Health, Ageing and Retirement in Europe (SHARE) study, held in 2013. This multidisciplinary and transnational study of 14 European countries and Israel recorded information on the health, socioeconomic status, social and family networks of non-institutionalized elderly people. ${ }^{41,42}$

The present cross-sectional study compared the data recorded in SHARE for the Spanish sample with the samples from Northern and Central European countries. The final sample comprised 3355 participants over 65 years in Spain and 18,834 from Central Europe (Switzerland, Luxembourg, Austria, Germany, Belgium and France) and Northern Europe (Denmark, Netherlands and Sweden) all countries with welfare models that present better indicators than Spain. ${ }^{43}$

\section{Variables and Instruments}

a) Sociodemographic data. Data regarding age (classified into age groups: 65-69 years, 70-74 years, 75-79 years, $\geq 80$ years), gender, marital status (married, single, divorced, widowed) and educational level $(0-5$ years of schooling, 6-8 years, 9-12 years, >12 years) were recorded.

b) Socioeconomic data. Employment status (retired, homemaker, in employment, unemployed/disabled) and difficulties making ends meet (with great difficulty, with some difficulty, fairly easily, easily) were recorded.

c) Exercise and activities. The performance of physical exercise and engagement in individual or social activities was assessed.

d) Physical health. Physical health (very good, good, fair, poor) and difficulties with ADL (none, 1-2, >2), were evaluated.

e) Depressive symptoms. The EURO-D scale was used to assess depression. This scale comprises 12 items (presence of depressive symptoms, pessimism, death wishes, guilt, irritability, tearfulness, fatigue, sleep problems, loss of interest and appetite, reduced concentration and loss of the capacity of enjoyment in the last month), using a cut-off point for clinically significant depressive symptomatology of $\geq 4 .{ }^{44,45}$ The answers were dichotomous (yes/no) and the final score ranged from 0 to 12 points, with higher scores indicating more depressive symptoms. Cronbach's alpha in the Eurodep Study ${ }^{46}$ was moderate, between 0.61 and 0.75 , while in the present study it was 0.71 .

f) Quality of life (QoL). The CASP-12 scale (Control, Autonomy, Pleasure and Self-realization), ${ }^{41,47}$ the shortened version of the original CASP-19 scale, ${ }^{48}$ was designed specifically for use in SHARE (CASP-12 v.1). ${ }^{49}$ The scale is composed of 12 items covering four areas (control, pleasure, autonomy and self-realization), which are evaluated on a 4-point Likert scale. The score range is $12-48$ 
points; QoL is rated as low (<35 points), moderate (35-37 points), high (38-39 points) and very high (>39 points).$^{48}$ Cronbach's alpha was 0.84 in the analysis of the psychometric properties of the scale, ${ }^{48}$ and 0.80 in the present study.

\section{Procedure}

The information was compiled during a 90-min interview at the participant's home which included questions about physical health, risk behaviors, cognitive performance, mental health, employment and pension, family and social relationships, financial issues, housing, family income, consumption, activities and expectations. ${ }^{41,47}$

\section{Statistical analysis}

A descriptive study of the clinical and sociodemographic characteristics of the sample was performed using means and standard deviation for continuous variables and frequencies for categorical variables. The contrasts of the categorical variables were performed using the Chi-square test and those of the continuous variables using Student's $t$ and $F$ (ANOVA). Data from the Spanish sample were compared with those from their Central-Northern European counterparts.

To complement the significance assessment, the effect size of the differences was calculated. For the difference between two means, we used Cohen's $(d)$, whose values indicated weak $(<0.5)$, moderate $(0.5-0.8)$ or strong $(>0.8)$ effects, ${ }^{50}$ and between several means, the eta squared $\left(\eta^{2}\right)$, which identifies weak $(<0.05)$, moderate $(0.06-0.13)$ or strong $(>0.13)^{51}$ effects. To evaluate the effect size of the differences in categorical variables, we used the Cramer $V(V)$ whose values depend on the degrees of freedom (df 1 = weak: $\leq 0.10$, moderate: $0.11-0.49$, strong: $\geq 0.50$; df 2 = weak: $\leq 0.07$, moderate: $0.08-0.34$, strong: $\geq 0.35$;f 3 = weak: $\leq 0.06$, moderate: $0.07-0.28$, strong: $\geq 0.29) .{ }^{50}$

To identify the influence of the independent variables on the QoL in the Spanish and Central-Northern European samples, two adjusted multiple linear regression analyses were performed in which all the variables were introduced in a single step. The coefficient of contribution (CC) of each variable was calculated according to the solution suggested by Guilford \& Fruchter ${ }^{52}$ : beta coefficient $\times$ correlation coefficient (Pearson) with the dependent variable.

Finally, to assess the main indicators of QoL and depression in Central and Northern Europe, each country participating in the study was analyzed individually, assessing the mean scores of CASP-12 and EURO-D, the frequency of scores $\geq 4$ on the EURO-D and the correlations between the CASP12 and the main variables. Correlations were assessed using the Pearson coefficient, whose values indicate weak $(<0.35)$, moderate $(0.35-0.50)$ and strong $(>0.50)^{53}$ effects.

In all the analyses population-weighted data was used, with the weights provided by SHARE in the specific module "gv_weights", which compensate for the unequal selection probabilities of the population parameters. ${ }^{42}$
The level of statistical significance for the contrasts of hypotheses was 0.05 . Statistical analysis was performed using SPSS v22.0 for Windows (SPSS Inc., Chicago).

\section{Results}

\section{Clinical and sociodemographic data of the sample}

The study population consisted of 22,189 participants, with a mean age of $74.9 \pm 7.1$ years. Women comprised $53.5 \%$ of the sample, $67.8 \%$ of participants were married and $19.6 \%$ were widowed; most were retired $(86.9 \%), 20.9 \%$ had difficulties making ends meet, $49.8 \%$ took some physical exercise and $86.4 \%$ engaged in some individual and/or social activity. Table 1 shows the clinical and sociodemographic data for the Spanish and Central-Northern European samples.

The greatest differences between the samples were in level of education; the Spanish sample had fewer years of schooling than their Central-Northern European counterparts $(\leq 8=69.9 \%$ vs. $26.4 \%, V=0.43)$. The percentage of retired people was lower in Spain $(65.2 \%$ vs $91.8 \%, V=0.33)$. The Spanish sample reported more economic difficulties (45.6\% vs. $20.2 \%, V=0.25$ ), and lower levels of participation in individual and/or social activities (56.8 vs. $92.1 \%$, $V=0.38$ ).

As regards depression, the mean overall EURO-D score in Spain was $2.9 \pm 2.7$ points, with $34.9 \%$ of the sample presenting clinically significant depressive symptomatology $(\geq 4)$. In the Central-Northern European sample the mean score was $2.4 \pm 2.1$ points, and clinically significant depressive symptoms were found in $27.4 \%$.

As for QoL (measured by CASP-12), the mean overall scores were $34.8 \pm 6.8$ in Spain and $38.5 \pm 5.8$ in CentralNorthern Europe $(p<0.001, d=0.58)$.

\section{Variables associated with specific levels of QoL}

The bivariate analysis (Table 2) indicated lower levels of QoL with higher ages in both samples, with a moderate effect size in Spain. As for gender, women had lower QoL in both groups, as did the widowed participants in Spain and the non-married participants in Central-Northern Europe. However, the results showed a weak effect size.

Less schooling was associated with a lower QoL, with a moderate effect size in Spain, as was being unemployed or disabled. In Central and Northern Europe, lower QoL was also associated with less schooling ( $\leq 8$ years) and unemployment, although in this group the effect sizes were not significant.

In both samples, engaging in individual or social activities and taking physical exercise were associated with a higher QoL, with moderate effect sizes.

The variables with the most negative influence on the perception of QoL were economic difficulties, ADL deficits, physical health and depression, which all presented strong effect sizes. Effect sizes were always higher in the Spanish sample. The complete results are shown in Table 2. 
Table 1 Clinical and sociodemographic data of the sample.

\begin{tabular}{|c|c|c|}
\hline & Spain & $\begin{array}{l}\text { Europe } \\
(C \& N)\end{array}$ \\
\hline & $n=3.355$ & $n=18.834$ \\
\hline \multicolumn{3}{|l|}{ Age } \\
\hline Mean (SD) & $74.9(7.1)$ & $\begin{array}{l}74.9 \\
(7.1)\end{array}$ \\
\hline $\begin{array}{l}\text { Range } \\
t(p) \mathrm{df} ; d\end{array}$ & $\begin{array}{l}65-104 \\
(<0.001) 1 ; 0.00\end{array}$ & $65-102$ \\
\hline \multicolumn{3}{|l|}{ Age, groups, $\%$} \\
\hline $65-69$ years & 30.5 & 27.8 \\
\hline $70-74$ years & 19.6 & 25.5 \\
\hline $75-79$ years & 23.0 & 19.7 \\
\hline $\begin{array}{l}\geq 80 \text { years } \\
\chi^{2}(p) \text { df; } V\end{array}$ & $\begin{array}{l}26.9 \\
(<0.001) 3 ; 0.05\end{array}$ & 27.0 \\
\hline \multicolumn{3}{|l|}{ Gender, \% } \\
\hline Men & 43.3 & 43.4 \\
\hline Women & 56.7 & 56.6 \\
\hline$\chi^{2}(p) \mathrm{df} ; V$ & $(<0.001) 1 ; 0.00$ & \\
\hline \multicolumn{3}{|l|}{ Marital status, \% } \\
\hline Married & 61.5 & 62.5 \\
\hline Widowed & 26.4 & 23.3 \\
\hline Single & 8.8 & 4.9 \\
\hline Divorced & 3.3 & 9.3 \\
\hline$\chi^{2}(p) \mathrm{df} ; V$ & $(<0.001) 3 ; 0.10$ & \\
\hline \multicolumn{3}{|c|}{ Educational level, groups, $\%$} \\
\hline $0-5$ years & 39.5 & 5.6 \\
\hline $6-8$ years & 30.4 & 20.9 \\
\hline $9-12$ years & 17.6 & 41.8 \\
\hline$>12$ years & 12.5 & 31.7 \\
\hline$\chi^{2}(p) \mathrm{df} ; V$ & $(<0.001) 3 ; 0.43$ & \\
\hline \multicolumn{3}{|c|}{ Employment status, \% } \\
\hline Retired & 65.2 & 91.8 \\
\hline Housework & 30.4 & 5.3 \\
\hline Working & 1.4 & 2.4 \\
\hline Unem./Disabled & 3.0 & 0.5 \\
\hline$\chi^{2}(p) \mathrm{df} ; V$ & $(<0.001) 3 ; 0.33$ & \\
\hline \multicolumn{3}{|c|}{ Economic difficulties, \% } \\
\hline Great difficulty & 15.0 & 3.7 \\
\hline Some difficulty & 30.6 & 16.6 \\
\hline Fairly easily & 30.5 & 31.4 \\
\hline Easily & 23.9 & 48.3 \\
\hline$\chi^{2}(p) \mathrm{df} ; V$ & $(<0.001) 3 ; 0.25$ & \\
\hline \multicolumn{3}{|l|}{ Exercise, \% } \\
\hline Yes & 33.5 & 48.3 \\
\hline No & 66.5 & 51.7 \\
\hline$\chi^{2}(p) d f ; V$ & $(<0.001) 1 ; 0.11$ & \\
\hline \multicolumn{3}{|l|}{ Activities, \% } \\
\hline No & 43.2 & 7.9 \\
\hline Yes & 56.8 & 92.1 \\
\hline$\chi^{2}(p) \mathrm{df} ; V$ & $(<0.001) 1 ; 0.38$ & \\
\hline
\end{tabular}

Table 1 (Continued)

\begin{tabular}{|c|c|c|}
\hline \multicolumn{3}{|l|}{ Physical health, \% } \\
\hline Very good & 12.4 & 18.1 \\
\hline Good & 35.2 & 39.7 \\
\hline Fair & 32.7 & 31.3 \\
\hline Poor & 19.7 & 10.9 \\
\hline$\chi^{2}(p) d f ; V$ & $(<0.001) 3 ; 0.11$ & \\
\hline \multicolumn{3}{|l|}{ ADL difficulties, \% } \\
\hline No & 79.8 & 81.6 \\
\hline $1-2$ & 9.3 & 10.9 \\
\hline$>2$ & 10.9 & 7.5 \\
\hline$\chi^{2}(p) d f ; V$ & $(<0.001) 2 ; 0.04$ & \\
\hline \multicolumn{3}{|l|}{ EURO-D } \\
\hline $\begin{array}{l}\text { Range 0-12 M } \\
\text { (SD) }\end{array}$ & $2.9(2.7)$ & $2.4(2.1)$ \\
\hline$t(p) \mathrm{df} ; d$ & $(<0.001) 1 ; 0.19$ & \\
\hline \multicolumn{3}{|l|}{ Cut-off point, \% } \\
\hline$<4$ & 65.1 & 72.6 \\
\hline $\begin{array}{l}\geq 4 \\
\chi^{2}(p) \mathrm{df} ; V\end{array}$ & $\begin{array}{l}34.9 \\
(<0.001) 1 ; 0.06\end{array}$ & 27.4 \\
\hline \multicolumn{3}{|l|}{ CASP-12 } \\
\hline $\begin{array}{l}\text { Range 12-48 M } \\
\text { (SD) }\end{array}$ & $34.8(6.8)$ & $\begin{array}{l}38.5 \\
(5.8)\end{array}$ \\
\hline$t(p) \mathrm{df} ; d$ & $(<0.001) 1 ; 0.58$ & \\
\hline
\end{tabular}

$t=$ Student test; $\chi^{2}=$ Chi-squared. Effect size: Cohen's $d=$ weak $(<0.50)$, moderate $(0.50-0.80) ; V=$ Cramer $(\mathrm{df} 1=$ weak: $\leq 0.10$, moderate: $0.11-0.49$, strong: $\geq 0.50$; df 2 =weak: $\leq 0.07$, moderate: $0.08-0.34$, strong: $\geq 0.35$; df $3=$ weak: $\leq 0.06$, moderate: $0.07-0.28$, strong: $\geq 0.29$ ). Moderate and strong effect sizes are shown in bold.

CASP-12 = quality of life; EURO-D = depression; $A D L$ = activities of daily living.

Europe (C\& N): Denmark, the Netherlands, Switzerland, Luxembourg, Austria, Sweden, Germany, Belgium, France.

\section{Multivariate analysis of variables associated with QoL (CASP-12)}

Two linear regression analysis were adjusted, one for Spain and one for Central-Northern Europe (Table 3). All the independent variables were introduced in a single step: age, gender, marital status, educational level, employment status, activities, level of exercise, economic difficulties, ADL deficits, physical health and depression. Variables with a high degree of collinearity and/or low coefficient of contribution $(\beta<0.07)$ were eliminated. The final model comprised the following variables: depression, physical health, economic difficulties, ADL deficits, educational level and physical exercise.

The variables associated with a lower QoL in both samples were the presence of depressive symptoms, poor physical health, difficulties making ends meet, and ADL deficits. Depression was the variable with the greatest difference between the two samples ( $\beta=0.444$ vs. 0.361 ), with Spain's coefficient of contribution being 10 points higher $(30.1 \%$ vs $20.1 \%$. Economic difficulties, ADL deficits and years of schooling had a slightly greater weight in Spain, while 
Table 2 Quality of life (CASP-12) and associated variables.

\begin{tabular}{|c|c|c|c|}
\hline & \multicolumn{2}{|c|}{ Mean (SD) } & \multirow{2}{*}{$\begin{array}{l}\text { Differences } \\
\text { Cohen's } d\end{array}$} \\
\hline & Spain & Europe $(C \& N)$ & \\
\hline \multicolumn{4}{|l|}{ Age } \\
\hline 65-69 years & $36.5(5.9)$ & $39.9(5.4)$ & 0.60 \\
\hline $70-74$ years & $35.9(6.7)^{\mathrm{a}}$ & $39.2(5.6)^{a}$ & 0.53 \\
\hline $75-79$ years & $34.6(6.6)^{b, d}$ & $38.4(5.8)^{b, d}$ & 0.61 \\
\hline$\geq 80$ years & $32.1(7.2)^{c, e, f}$ & $36.7(6.1)^{c, e, f}$ & 0.68 \\
\hline $\bar{F}(p) \eta^{2}$ & $(<0.001) 0.06$ & $(<0.001) 0.04$ & \\
\hline \multicolumn{4}{|l|}{ Gender } \\
\hline Male & $36.1(6.2)$ & $39.0(5.7)$ & 0.48 \\
\hline Female & $33.8(7.1)$ & $38.2(5.9)$ & 0.67 \\
\hline$t(p) d$ & $(<0.001) 0.34$ & $(<0.001) 0.13$ & \\
\hline \multicolumn{4}{|l|}{ Marital status } \\
\hline Married & $35.5(6.4)$ & $39.2(5.5)$ & 0.62 \\
\hline Single & $36.7(7.2)^{\mathrm{a}}$ & $37.2(6.1)^{\mathrm{a}}$ & 0.07 \\
\hline Divorced & $34.3(7.9)^{\mathrm{b}, \mathrm{d}}$ & $37.4(6.1)^{b, d}$ & 0.43 \\
\hline Widowed & $32.5(6.8)^{c, e, f}$ & $37.5(6.3)^{c, e, f}$ & 0.76 \\
\hline$F(p) \eta^{2}$ & $(<0.001) 0.04$ & $(<0.001) 0.02$ & \\
\hline \multicolumn{4}{|l|}{ Education level } \\
\hline 0-5 years & $32.4(6.8)$ & $37.6(6.6)$ & 0.77 \\
\hline $6-8$ years & $35.8(6.4)^{\mathrm{a}}$ & $37.2(6.0)^{\mathrm{a}}$ & 0.22 \\
\hline $9-12$ years & $36.4(6.2)^{b, d}$ & $38.5(5.8)^{\mathrm{b}, \mathrm{d}}$ & 0.34 \\
\hline$>12$ years & $38.5(5.4)^{\mathrm{c}, \mathrm{e}, \mathrm{f}}$ & $39.7(5.2)^{c, e, f}$ & 0.22 \\
\hline$F(p) \eta^{2}$ & $(<0.001) 0.10$ & $(<0.001) 0.02$ & \\
\hline \multicolumn{4}{|l|}{ Employment status } \\
\hline Working & $38.7(5.1)$ & $41.6(4.8)$ & 0.58 \\
\hline Retired & $36.0(6.2)^{\mathrm{a}}$ & $38.6(5.7)^{\mathrm{a}}$ & 0.43 \\
\hline Housework & $32.8(7.1)^{b, d}$ & $38.3(6.1)^{b, d}$ & 0.83 \\
\hline Unem./Disabled & $28.2(6.3)^{\mathrm{c}, \mathrm{e}, \mathrm{f}}$ & $34.4(6.4)^{c, e, f}$ & 0.97 \\
\hline$F(p) \eta^{2}$ & $(<0.001) 0.07$ & $(<0.001) 0.00$ & \\
\hline \multicolumn{4}{|l|}{ Activities } \\
\hline No & $32.3(6.9)$ & $34.6(6.9)$ & 0.33 \\
\hline Yes & $36.7(6.1)$ & $39.0(5.5)$ & 0.39 \\
\hline$t(p) d$ & $(<0.001) 0.67$ & $(<0.001) 0.70$ & \\
\hline \multicolumn{4}{|l|}{ Exercise } \\
\hline Yes & $37.2(5.2)$ & $40.2(4.9)$ & 0.59 \\
\hline No & $33.6(7.2)$ & $37.0(6.2)$ & 0.50 \\
\hline$t(p) d$ & $(<0.001) 0.57$ & $(<0.001) 0.57$ & \\
\hline \multicolumn{4}{|c|}{ Economic difficulties } \\
\hline Great difficulty & $29.8(6.8)$ & $33.4(6.8)$ & 0.52 \\
\hline Some difficulty & $33.3(6.2)^{\mathrm{a}}$ & $35.1(5.9)^{\mathrm{a}}$ & 0.29 \\
\hline Fairly easily & $35.6(6.3)^{b, d}$ & $38.4(5.2)^{b, d}$ & 0.48 \\
\hline Easily & $38.7(5.2)^{c, e, f}$ & $40.4(5.1)^{\mathrm{c}, \mathrm{e}, \mathrm{f}}$ & 0.33 \\
\hline$F(p) \eta^{2}$ & $(<0.001) 0.17$ & $(<0.001) 0.13$ & \\
\hline \multicolumn{4}{|l|}{ ADL difficulties } \\
\hline No & 36.5 (5.9) & $39.6(5.2)$ & 0.55 \\
\hline $1-2$ & $29.8(5.5)^{\mathrm{a}}$ & $35.2(5.5)^{\mathrm{a}}$ & 0.98 \\
\hline$>2$ & $26.6(5.8)^{b, d}$ & $31.6(6.1)^{b, d}$ & 0.84 \\
\hline$F(p) \eta^{2}$ & $(<0.001) 0.25$ & $(<0.001) 0.16$ & \\
\hline
\end{tabular}


Table 2 (Continued)

\begin{tabular}{|c|c|c|c|}
\hline & \multicolumn{2}{|c|}{ Mean (SD) } & \multirow{2}{*}{$\begin{array}{l}\text { Differences } \\
\text { Cohen's } d\end{array}$} \\
\hline & Spain & Europe $(C \& N)$ & \\
\hline \multicolumn{4}{|c|}{ Physical health } \\
\hline Very good & $40.0(4.6)$ & $42.6(4.0)$ & 0.60 \\
\hline Good & $37.5(5.4)^{\mathrm{a}}$ & $40.0(4.7)^{\mathrm{a}}$ & 0.49 \\
\hline Fair & $34.1(5.7)^{\mathrm{b}, \mathrm{d}}$ & $36.8(5.4)^{\mathrm{b}, \mathrm{d}}$ & 0.48 \\
\hline Poor & $27.9(6.2)^{c, e, f}$ & $32.1(6.3)^{c, e, f}$ & 0.67 \\
\hline$F(p) \eta^{2}$ & $(<0.001) 0.32$ & $(<0.001) 0.25$ & \\
\hline \multicolumn{4}{|l|}{ EURO-D } \\
\hline$<4$ & $37.7(5.0)$ & $40.2(4.8)$ & 0.51 \\
\hline$\geq 4$ & $29.4(6.5)$ & $34.0(6.0)$ & 0.73 \\
\hline$t(p) d$ & $(<0.001) 1.43$ & $(<0.001) 1.14$ & \\
\hline
\end{tabular}

Table 3 CASP-12. Multiple linear regression.

\begin{tabular}{|c|c|c|c|c|c|}
\hline \multicolumn{6}{|c|}{ Spain } \\
\hline CASP-12 & $r^{2}=0.586$ & $\beta$ & $p$ & $r$ & $\mathrm{CC}$ \\
\hline EURO-D, depression & (Higher) & 0.444 & $<0.001$ & 0.679 & 30.1 \\
\hline Physical health & (Lower) & -0.200 & $<0.001$ & -0.546 & 10.9 \\
\hline Economic difficulties & (More) & 0.205 & $<0.001$ & 0.423 & 8.7 \\
\hline ADL difficulties & (More) & 0.121 & $<0.001$ & 0.461 & 5.6 \\
\hline Education & (Lower) & -0.085 & $<0.001$ & -0.335 & 2.8 \\
\hline Exercise & (No) & 0.021 & $<0.001$ & 0.238 & 0.5 \\
\hline$F(\mathrm{df}), p$ & \multicolumn{5}{|c|}{$629.2(6,3013)<0.001$} \\
\hline Collinearity: Tol./VIF & \multicolumn{5}{|c|}{$0.65-0.88 / 1.13-1.53$} \\
\hline \multicolumn{6}{|c|}{ Europe (C \& N) } \\
\hline CASP-12 & $r^{2}=0.453$ & $\beta$ & $p$ & $r$ & $\mathrm{CC}$ \\
\hline EURO-D, depression & (Higher) & 0.361 & $<0.001$ & 0.557 & 20.1 \\
\hline Physical health & (Lower) & -0.221 & $<0.001$ & -0.493 & 10.9 \\
\hline Economic difficulties & (More) & 0.217 & $<0.001$ & 0.362 & 7.8 \\
\hline ADL difficulties & (More) & 0.123 & $<0.001$ & 0.355 & 4.4 \\
\hline Education & (Higher & 0.003 & $<0.001$ & 0.144 & 0.0 \\
\hline Exercise & (No) & 0.076 & $<0.001$ & 0.275 & 2.1 \\
\hline$F(\mathrm{df}), p$ & \multicolumn{5}{|c|}{$2137.7(6.17322)<0.001$} \\
\hline Collinearity: Tol./VIF & \multicolumn{5}{|c|}{$0.71-0.92 / 1.06-1.40$} \\
\hline
\end{tabular}

$F$, ANOVA; $r^{2}$, coefficient of determination; $\beta$, standardized beta coefficient $>0.07 ; t$, Student's test; $r$, Pearson correlation (order-zero); CC, coefficient of contribution (\%), $((\beta \times r) \times 100)]$. Tol, tolerance; VIF, variation inflation factor.

CASP-12 = quality of life.

physical exercise exerted a greater weight in the CentralNorthern European countries.

\section{Main indicators of QoL and depression in Europe}

The differences in QoL mean scores (CASP-12) between the countries were moderate. The highest scores were recorded in Denmark, the Netherlands and Switzerland, and the lowest in Spain, France and Belgium (Table 4).
The differences in EURO-D mean scores between the countries had a weak effect size, while the differences in the percentages of population with clinically significant depressive symptomatology $(\geq 4)$ had a strong effect size. The highest percentages of depression were recorded in Spain, France, Belgium and Luxembourg and the lowest in Denmark, the Netherlands, Switzerland and Sweden.

The correlations between the CASP-12 and the EUROD were moderate or strong in all countries $(r=-0.59)$, and were somewhat lower with other variables: physical health $(r=0.51)$, ADL deficits $(r=-0.40)$ and economic difficulties 
Table 4 Principal indicators of QoL and depression in Europe.

\begin{tabular}{|c|c|c|c|c|c|c|c|c|c|c|c|}
\hline \multirow[t]{2}{*}{ Countries } & \multirow[t]{2}{*}{$n$} & \multirow{2}{*}{$\begin{array}{l}\text { CASP-12 } \\
\text { Mean (SD) }\end{array}$} & \multicolumn{2}{|c|}{ EURO-D } & \multicolumn{4}{|c|}{ CASP-12 correlations } & \multicolumn{3}{|c|}{ EURO-D correlations } \\
\hline & & & Mean (SD) & $\geq 4(\%)$ & $\begin{array}{l}\text { EURO-D } \\
r\end{array}$ & $\begin{array}{l}\text { Health } \\
r\end{array}$ & $\begin{array}{l}\mathrm{ADL} \\
r\end{array}$ & $\begin{array}{l}\text { Econ. Diff. } \\
r\end{array}$ & $\begin{array}{l}\text { Health } \\
r\end{array}$ & $\begin{array}{l}\mathrm{ADL} \\
r\end{array}$ & $\begin{array}{l}\text { Econ. Diff. } \\
r\end{array}$ \\
\hline Denmark & 1.901 & $41.2(5.1)$ & $1.6(1.7)$ & 15.8 & -0.57 & 0.52 & \multicolumn{2}{|c|}{$-0.42-0.28$} & -0.45 & 0.33 & 0.17 \\
\hline Netherlands & 2.113 & $40.5(5.4)$ & $1.8(1.9)$ & 17.7 & -0.54 & 0.44 & \multicolumn{2}{|c|}{$-0.29-0.32$} & -0.39 & 0.26 & 0.21 \\
\hline Switzerland & 1.611 & $40.5(4.9)$ & $1.9(1.7)$ & 19.1 & -0.43 & 0.42 & \multicolumn{2}{|c|}{$-0.29-0.36$} & -0.37 & 0.23 & 0.13 \\
\hline Luxembourg & 655 & $39.6(5.4)$ & $2.5(2.2)$ & 29.4 & -0.53 & 0.46 & \multicolumn{2}{|c|}{$-0.35-0.26$} & -0.48 & 0.33 & 0.12 \\
\hline Austria & 2.278 & $39.3(5.8)$ & $2.1(2.0)$ & 22.5 & -0.57 & 0.49 & \multicolumn{2}{|c|}{$-0.36-0.34$} & -0.49 & 0.34 & 0.20 \\
\hline Sweden & 2.765 & $39.1(5.2)$ & $2.0(1.8)$ & 19.1 & -0.47 & 0.47 & \multicolumn{2}{|c|}{$-0.28-0.33$} & -0.42 & 0.22 & 0.21 \\
\hline Germany & 2.545 & $38.6(5.7)$ & $2.3(2.0)$ & 24.5 & -0.54 & 0.47 & \multicolumn{2}{|c|}{$-0.36-0.40$} & -0.42 & 0.35 & 0.20 \\
\hline Belgium & 2.632 & $37.7(6.1)$ & $2.4(2.2)$ & 27.8 & -0.54 & 0.49 & \multicolumn{2}{|c|}{$-0.38-0.31$} & -0.47 & 0.35 & 0.19 \\
\hline France & 2.334 & $37.5(6.1)$ & $3.0(2.3)$ & 37.9 & -0.59 & 0.53 & \multicolumn{2}{|c|}{$-0.43-0.33$} & -0.46 & 0.33 & 0.18 \\
\hline Spain & 3.355 & $34.8(6.8)$ & $2.9(2.7)$ & 34.9 & -0.68 & 0.56 & \multicolumn{2}{|c|}{$-0.46-0.42$} & -0.50 & 0.47 & 0.27 \\
\hline$F / \chi^{2} ; p$ & & $<0.001$ & $<0.001$ & $<0.001$ & $<0.001$ & $<0.001$ & \multicolumn{2}{|c|}{$<0.001<0.001$} & $<0.001$ & $<0.001$ & $<0.001$ \\
\hline Effect size & & $\eta^{2}=0.07$ & $\eta^{2}=0.03$ & $V=0.16$ & $6-0.59$ & 0.51 & \multicolumn{2}{|c|}{$-0.40-0.41$} & -0.46 & 0.37 & 0.23 \\
\hline Central-North. & 18.834 & $38.5(5.8)$ & $2.4(2.1)$ & 27.4 & -0.57 & 0.50 & \multicolumn{2}{|c|}{$-0.38-0.37$} & -0.44 & 0.33 & 0.20 \\
\hline Spain & 3.355 & $34.8(6.8)$ & $2.9(2.7)$ & 34.9 & -0.68 & 0.56 & \multirow{3}{*}{\multicolumn{2}{|c|}{$-0.46-0.42$}} & -0.50 & 0.47 & 0.27 \\
\hline$t / \chi^{2} ; p$ & & $<0.001$ & $<0.001$ & $<0.001$ & & & & & & & \\
\hline Effect size & & $d=0.58$ & $d=0.20$ & $V=0.06$ & & & & & & & \\
\hline
\end{tabular}

$F=$ ANOVA; $\chi^{2}=$ Chi-squared. $t=$ Student's test; $r=$ Pearson's correlation; effect size: eta-squared $\left(\eta^{2}\right)=$ weak $(<0.05)$, moderate $(0.06-0.13)$, strong $(>0.13) ; V=$ Cramer, df $1=$ weak $(\leq 0.10)$, moderate $(0.11-0.49)$, df $>5=$ moderate $(0.13-0.22)$, strong $(>0.22)$; correlation: weak $(<0.35)$, moderate $(0.35-0.50)$, strong $(>0.50)$; Cohen', $d=$ weak $(<0.50)$, moderate $(0.50-0.80)$, strong $(>0.80)$. Moderate and strong effect sizes are shown in bold.

CASP-12 = quality of life; EURO-D = depression. Physical health. Econ. Diff. = economic difficulties; $A D L=$ difficulties in activities of daily living.

$(r=-0.41)$. The Spanish sample showed the highest correlations between QoL and all the variables, with a particularly high correlation between CASP-12 and EURO-D $(r=-0.68)$.

The correlations of the EURO-D with the variables analyzed in all the countries taken together had a lower effect size than those of the CASP-12, and the relationship between depression and economic difficulties was not very significant. In Spain, the same trend occurred, although the correlations of EURO-D with health $(r=-0.50)$ and ADL difficulties $(r=0.47)$ continued to have a relevant effect. The complete data are shown in Table 4.

Years of education showed notable differences between Spain and the rest of the countries. While in Spain the correlation with the CASP- 12 was 0.33 , in the rest of countries it had a very weak value of 0.14 . The correlations of years of education with EURO-D were low in all countries.

\section{Discussion}

\section{Relationship between clinical and sociodemographic variables and QoL}

The first objective of the study was to explore the relationship between clinical and sociodemographic variables and QoL in people older than 65 years in samples from Spain and from Central-Northern European countries. The analysis showed that the most relevant variables associated with a lower QoL in both samples were the presence of depressive symptoms, poor physical health, difficulties performing ADL, economic difficulties and not engaging in social activities and/or physical exercise.

These results corroborate those of previous studies which have indicated negative correlations between depression and QoL. ${ }^{9,10}$ Regarding physical health, several studies have found an association between poor physical health and a higher presence of depressive symptoms, greater functional decline and more difficulties performing ADL. ${ }^{3-6}$ Studies of the practice of leisure activities indicate that they improve QoL, ${ }^{21-23}$ decreasing the risk of marginalization and/or loneliness in older adults. ${ }^{20,54}$ Likewise, the practice of physical exercise appears to be associated with better cognitive functioning, a reduction in depressive symptoms, and better well-being and higher QoL in the elderly. ${ }^{17,19}$ Finally, economic difficulties are an obstacle to high QoL, due to the associated feelings of anxiety and insecurity. ${ }^{11-13}$

\section{Differential aspects in QoL in Spain and Europe}

The associations of certain variables with QoL present differences between the samples from Spain and CentralNorthern Europe. While older age, unemployment and lower educational level are related with a lower QoL in Spain, in Central-Northern Europe these associations were not significant. Our results for the Spanish sample are in agreement with previous studies which associated younger age, employment and high levels of schooling with higher QoL. ${ }^{3-6,11-13,24,35,36,56}$

On the other hand, poor physical health, ADL deficits and more economic difficulties were more strongly associated 
with a lower QoL in Spain than in the other countries analyzed. Some authors attribute the differences in the variables associated with depression and QoL between countries to the social welfare models in place. ${ }^{39,55}$ Other studies associate economic difficulties with poor health and the presence of depression, especially in southern Europe, stressing that social welfare models may be able to mitigate and/or reverse the effects of these variables on QoL in older adults. ${ }^{57}$

Some authors relate possible differences in the perception of QoL with national characteristics and cultural factors, ${ }^{58}$ while others emphasize economic aspects and education as the key determining variables. ${ }^{38}$ The type of social policies implemented in different countries, and specifically their level of generosity, may also influence the differences in perceptions of QoL. ${ }^{59}$ In their study of the variables affecting loneliness and depression in different European regions, Van Tilburg and Dykstra ${ }^{60}$ concluded that social welfare models should be taken into account as well as individual and cultural aspects.

In a study using data from the 2002 World Health Survey to compare seven social welfare models (Conservative, Southeast Asia, Eastern Europe, Latin America, Liberal, South and Social Democratic), respondents from countries in Southern Europe were more likely to have presented depressive symptoms in the last 12 months. ${ }^{61}$ Also coinciding with the trend found in the present study, other research has found associations between economic income and social inequality and depression and lower QoL, with worse results in Spain, Italy and Greece. ${ }^{62-65}$

However, although the indicators suggest lower QoL in Spain, the suicide rate in older people $(\times 100.000)$ is lower $(50-69$ years $=9.6 / \geq 70$ years $=13.9)$ than in the European countries analyzed (50-69 years $=19.8 / \geq 70$ years $=20.9) \cdot{ }^{39,66}$ Some authors attribute this to the greater strength of the family system in Spain which may act as a protective factor. ${ }^{67}$

\section{Quality of life and depression}

The analysis of the data highlights the important association between depression and QoL in all the countries analyzed, and particularly in the Spanish sample. They are two different construct, although it could be said that the assessment of the QoL encompasses a wider scope than the depression itself, being more closely related to the analyzed variables, for example, the economic difficulties in the whole of the countries analyzed, and other variables such as the years of education in Spain.

\section{Limitations and future lines of research}

Our study has a number of limitations. First, because of the data collection methodology used in the SHARE project, no additional professional evaluation is available; this means that the subjective perceptions recorded cannot be assessed objectively.

Second, cognitive aspects of QoL have not been taken into account in this paper, even though cognitive performance influences and conditions the possible presence of depressive symptoms and consequently QoL. Therefore, a future line of research would be the study of cognitive aspects to evaluate the variables associated with lower performance and their relation to depression and QoL itself.

Finally, the differences in the family system in the countries analyzed and their repercussions in the care of the elderly may well have implications for the perception of QoL and should be assessed in more depth in future studies.

\section{Conclusions}

The main variables associated with a lower QoL in Spain and in Central-Northern Europe were the presence of clinically significant depressive symptoms, poor physical health, difficulties with $A D L$, economic difficulties and not engaging in social activities or physical exercise. Depression also showed a significant correlation with lower physical health and ADL deficits, although but not with economic difficulties.

As differential aspects, the Spanish sample showed more deficient values in all the variables associated with QoL, emphasizing the high inverse correlation between QoL and depression and the high direct correlation between QoL and years of education.

\section{Funding}

7th Framework Program of the European Commission (SHARE M4, No. 261982). Project: SHARE (Survey of Health, Ageing and Retirement in Europe).

\section{Conflict of interest}

The authors declare that there is no conflict of interest.

\section{Acknowledgment}

This paper uses data from SHARE Wave 5 release 1.0 .0 , as of March 31st 2015 (doi:10.6103/SHARE.w5.100). The SHARE data collection has been primarily funded by the European Commission through the 5th Framework Program (project QLK6-CT-2001-00360 in the thematic program Quality of Life), through the 6th Framework Program (projects SHARE13, RII-CT-2006-062193, COMPARE, CIT5-CT-2005-028857, and SHARELIFE, CIT4-CT-2006-028812) and through the 7th Framework Program (SHARE-PREP, No. 211909, SHARE-LEAP, No. 227822 and SHARE M4, No. 261982). Additional funding from the U.S. National Institute on Aging (U01 AG0974013S2, P01 AG005842, P01 AG08291, P30 AG12815, R21 AG025169, Y1-AG-4553-01, IAG BSR06-11 and OGHA 04-064) and the German Ministry of Education and Research, as well as from various national sources is gratefully acknowledged (see www.share-project.org for a full list of funding institutions).

\section{References}

1. De Araújo AA, Rebouças Barbosa RA, De Menezes MS, De Medeiros II, De Araújo RF Jr, de Medeiros CA. Quality of life, family support, and comorbidities in institutionalized elders with and without symptoms of depression. Psychiatr Q. 2016;87:281-91. 
2. Elosua P. Subjective values of quality of life dimensions in elderly people. A SEM preference model approach. Soc Indic Res. 2011;104:427-37.

3. Fusco O, Ferrini A, Santoro M, Lo Monaco MR, Gambassi G, Cesari M. Physical function and perceived quality of life in older persons. Aging Clin Exp Res. 2012;24:68-73.

4. Low G, Molzahn AE, Schopflocher D. Attitudes to aging mediate the relationship between older peoples' subjective health and quality of life in 20 countries. Health Qual Life Outcomes. 2013;11:146.

5. Palgi Y, Shrira A, Zaslavsky O. Quality of life attenuates agerelated decline in functional status of older adults. Qual Life Res. 2015;24:1835-43.

6. Requena C, López V, Ortiz T. Satisfaction with life related to functionality in active elderly people. Actas Esp Psiquiatr. 2009;37:61-7.

7. Pinquart M, Sörensen S. Influences of socioeconomic status, social network, and competence on subjective well-being in later life: a meta-analysis. Psychol Aging. 2000;15:187-224.

8. Sparks M, Zehr A, Painter B. Predictors of life satisfaction: perceptions of older community-dwelling adults. J Gerontol Nurs. 2004;30:47-53.

9. Ponte C, Almeida V, Fernandes L. Suicidal ideation, depression and quality of life in the elderly: study in a gerontopsychiatric consultation. Span J Psychol. 2014;17:E14.

10. Unalan D, Gocer S, Basturk M, Baydur H, Ozturk A. Coincidence of low social support and high depressive score on quality of life in elderly. Eur Geriatr Med. 2015;6:319-24.

11. Netuveli G, Wiggins RD, Hildon Z, Montgomery SM, Blane D. Quality of life at older ages: evidence from the English longitudinal study of aging (wave 1). J Epidemiol Community Health. 2006;60:357-63.

12. Von dem Knesebeck O, Wahrendorf M, Hyde M, Siegrist J. Socioeconomic position and quality of life among older people in 10 European countries: results of the share study. Age Soc. 2007;27:269-84.

13. Bielderman A, de Greef MH, Krijnen WP, van der Schans CP. Relationship between socioeconomic status and quality of life in older adults: a path analysis. Qual Life Res. 2015;24:1697-705.

14. Bray I, Gunnell D. Suicide rates, life satisfaction and happiness as markers for population mental health. Soc Psyhiatry Psychiatr Epidemiol. 2006;41:333-7.

15. Low G, Molzahn AE. Predictors of quality of life in old age: a cross-validation study. Res Nurs Health. 2007;30:141-50.

16. Ziółkowski A, Błachnio A, Pąchalska M. An evaluation of life satisfaction and health - quality of life of senior citizens. Ann Agric Environ Med. 2015;22:147-51.

17. Elavsky S, McAuley E, Motl RW, Konopack JF, Marquez DX, Hu $L$, et al. Physical activity enhances long-term quality of life in older adults: efficacy, esteem, and affective influences. Ann Behav Med. 2005;30:138-45.

18. Dragomirecká E, Bartonová J, Eisemann M, Kalfoss M, Kilian R, Martiny K, et al. Demographic and psychosocial correlates of quality of life in the elderly from a cross-cultural perspective. Clin Psychol Psychother. 2008;15:193-204.

19. Langlois F, Vu TT, Chassé K, Dupuis G, Kergoat MJ, Bherer L. Benefits of physical exercise training on cognition and quality of life in frail older adults. J Gerontol B Psychol Sci Soc Sci. 2013;68:400-4.

20. Barcelos-Ferreira R, Nakano EY, Steffens DC, Bottino CM. Quality of life and physical activity associated to lower prevalence of depression in community-dwelling elderly subjects from Sao Paulo. J Affect Disord. 2013;150:616-22.

21. Lee JH, Lee JH, Park SH. Leisure activity participation as predictor of quality of life in Korean urban-dwelling elderly. Occup Ther Int. 2014;21:124-32.

22. Choi Y, Lee KS, Shin J, Kwon JA, Park EC. Effects of a change in social activity on quality of life among middle-aged and elderly Koreans: analysis of the Korean longitudinal study of aging (2006-2012). Geriatr Gerontol Int. 2017;17:132-41.

23. Aragonés E, López-Cortacans $\mathrm{G}$. Relation between the remission of depression and quality of life perceived by the patient. Actas Esp Psiquiatr. 2016;44:79-82.

24. Layte R, Sexton E, Savva G. Quality of life in older age: evidence from an Irish cohort study. J Am Geriatr Soc. 2013;61:S299-305.

25. Bilgili N, Arpaci F. Quality of life of older adults in Turkey. Arch Gerontol Geriatr. 2014;59:415-21.

26. Cherepanov D, Palta M, Fryback DG, Robert SA. Gender differences in health-related quality-of-life are partly explained by sociodemographic and socioeconomic variation between adult men and women in the US: evidence from four US nationally representative data sets. Qual Life Res. 2010;19:1115-24.

27. Hinz A, Singer S, Brähler E. European reference values for the quality of life questionnaire EORTC QLQ-C30: results of a German investigation and a summarizing analysis of six European general population normative studies. Acta Oncol. 2014;53:958-65.

28. Juul T, Petersen MA, Holzner B, Laurberg S, Christensen P, Grønvold M. Danish population-based reference data for the EORTC QLQ-C30: associations with gender, age and morbidity. Qual Life Res. 2014;23:2183-93.

29. Mielck A, Vogelmann M, Leidl R. Health-related quality of life and socioeconomic status: inequalities among adults with a chronic disease. Health Qual Life Outcomes. 2014;12:58.

30. West C, Paul SM, Dunn L, Dhruva A, Merriman J, Miaskowski C. Gender differences in predictor of quality of life at the initiation of radiation therapy. Oncol Nurs Forum. 2015;42:507-16.

31. Pinkas J, Gujski M, Humeniuk E, Raczkiewicz D, Bejga P, Owoc A, et al. State of health and quality of life of women at advanced age. Med Sci Monit. 2016;22:3095-105.

32. Kalpakjian CZ, Houlihan B, Meade MA, Karana-Zebari D, Heinemann AW, Dijkers MP, et al. Marital status, marital transitions, well-being, and spinal cord injury: an examination of the effects of sex and time. Arch Phys Med Rehabil. 2011;92:433-40.

33. Bourassa KJ, Knowles LM, Sbarra DA, O'Connor MF. Absent but not gone: interdependence in couples' quality of life persists after a partner's death. Psychol Sci. 2016;27:270-81.

34. Inouye K, Pedrazzani ES. Educational status, social economic status and evaluation of some dimensions of octogenarians' quality of life. Rev Lat Am Enfermagem. 2007. Spec No. 742-7.

35. Marmot M. Social determinants of health inequalities. Lancet. 2005;365:1099-104.

36. Vassilev I, Rogers A, Sanders C, Cheraghi-Sohi S, Blickem C, Brooks $\mathrm{H}$, et al. Social status and living with a chronic illness: an exploration of assessment and meaning attributed to work and employment. Chronic IIIn. 2014;10:273-90.

37. Delhey J, Dragolov G. Happier together. Social cohesion and subjective well-being in Europe. Int J Psychol. 2015;51:163-76.

38. Niedzwiedz CL, Katikireddi SV, Pell JO, Mitchell R. The association between life course, socioeconomic position and life satisfaction in different welfare states: European comparative study of individuals in early old age. Age Age. 2014;43: 431-6.

39. Conde-Sala JL, Portellano-Ortiz C, Calvó-Perxas L, Garre-Olmo J. Quality of life in people aged 65 + in Europe: associated factors and models of social welfare - analysis of data from the SHARE project (Wave 5). Qual Life Res. 2017;26:1059-70.

40. Von dem Knesebeck O, Hyde M, Higgs P, Kupfer A, Siegrist J. Quality of life and well-being. In: Börsch-Supan A, Brugiavini A, Jürges $\mathrm{H}$, Mackenbach J, Siegrist J, Weber J, editors. Health, ageing and retirement in Europe - first results from the survey of health, ageing and retirement in Europe. Mannheim: Mannheim Research Institute for the Economics of Aging (MEA); 2005. p. 199-203.

41. Börsch-Supan A, Brandt M, Hunkler C, Kneip T, Korbmacher J, Malter F, et al. Data resource profile: the Survey of Health, 
Ageing and Retirement in Europe (SHARE). Int J Epidemiol. 2013;42:992-1001.

42. Malter F, Börsch-Supan A. SHARE wave 5: innovations \& methodology. Munich: MEA, Max Planck Institute for Social Law and Social Policy; 2015.

43. European Commission. Quality of life in Europe: subjective wellbeing. Luxembourg: Publications Office of the European Union; 2013.

44. Larraga L, Saz P, Dewey ME, Marcos G, and the ZARADEMP Workgroup. Validation of the Spanish version of the EURO-D Scale: an instrument for detecting depression in older people. Int J Geriatr Psychiatry. 2006;21:1199-205.

45. Prince MJ, Reischies F, Beekman ATF, Fuhrer R, Jonker C, Kivela $\mathrm{SL}$, et al. Development of the EURO-D scale - a European Union initiative to compare symptoms of depression in 14 European centers. Br J Psychiatry. 1999;174:330-8.

46. Guerra M, Ferri C, Llibre J, Prina AM, Prince M. Psychometric properties of EURO-D, a geriatric depression scale: a crosscultural validation study. BMC Psychiatry. 2015;15:12.

47. Börsch-Supan A, Brugiavini A, Jurges H, Mackenbach J, Siegrist $\mathrm{J}$, Weber $\mathrm{G}$. Health ageing and retirement in Europe: first results from the survey of health, ageing and retirement in Europe. Mannheim: Mannheim Research Institute for the Economics of Aging; 2005.

48. Hyde M, Wiggins RD, Higgs P, Blane DB. A measure of quality of life in early old age: the theory, development and properties of a needs satisfaction model (CASP-19). Aging Ment Health. 2003;7:86-94.

49. Kim GR, Netuveli G, Blane D, Peasey A, Malyutina S, Simonova G, et al. Psychometric properties and confirmatory factor analysis of the CASP-19, a measure of quality of life in early old age: the HAPIEE study. Aging Ment Health. 2015;19:595-609.

50. Cohen J. Statistical power analysis for the behavioral sciences. 2nd ed. Hillsdale, NJ: Lawrence Erlbaum; 1988.

51. Cohen J. Eta-squared and partial eta-squared in fixed factor ANOVA designs. Educ Psychol Meas. 1973;33:107-12.

52. Guilford JP, Fruchter B. Fundamental statistics in psychology and education. 5th ed. New York: McGraw-Hill; 1973.

53. Guyatt GH, King DR, Feeny DH, Stubbing D, Goldstein RS. Generic and specific measurement of health-related quality of life in a clinical trial of respiratory rehabilitation. J Clin Epidemiol. 1999;52:187-92.

54. Murray CJ, López AD. Global mortality, disability and the contribution of risk factors: global burden of disease study. Lancet. 1997;349:1436-42.

55. Eikemo TA, Bambra C, Judge K, Ringdal K. Welfare state regimes and differences in self-perceived health in Europe: a multilevel analysis. Soc Sci Med. 2008;66:2281-95.
56. De la Cámara C, Saz P, López-Antón R, Ventura T, Día JL, Lobo A. Depression in the elderly community: I. Prevalence by different diagnostic criteria and clinical profile. Eur J Psychiat. 2008;22:131-40.

57. Levecque K, Van Rossem R, De Boyser K, Van de Velde S, Bracke P. Economic hardship and depression across the life course: the impact of welfare state regimes. J Health Soc Behav. 2011;52:262-76.

58. Calha A, Postigo S, Health. wellbeing and conviviality of the elderly. The Portuguese, Spanish and European situation. Rev Enferm. 2016;39:8-17.

59. Lundberg O, Yngwe MA, Stjärne MK, Elstad JI, Ferrarini $T$, Kangas 0 , et al. The role of welfare state principles and generosity in social policy programs for public Health: an international comparative study. Lancet. 2008;372: 1633-40.

60. Van Tilburg TG, Dykstra PA. Differences in older adults' loneliness and depression across Europe. In: Dykstra PA, editor. Ageing, intergenerational solidarity and age-specific vulnerabilities. The Hague: NIDI; 2008. p. 141-53.

61. Chung H, Ng E, Ibrahim S, Karlsson B, Benach J, Espelt A, et al. Welfare state regimes, gender, and depression: a multilevel analysis of middle and high income countries. Int J Environ Res Public Health. 2013;10:1324-41.

62. Ladin K, Daniels N, Kawachi I. Exploring the relationship between absolute and relative position and late-life depression: evidence from 10 European countries. Gerontologist. 2010;50:48-59.

63. Castro-Costa E, Dewey M, Stewart R, Banerjee S, Huppert F, Mendonca-Lima C, et al. Prevalence of depressive symptoms and syndromes in later life in ten European countries: the SHARE study. Br J Psychiatry. 2007;191:393-401.

64. Gallagher D, Savva GM, Kenny R, Lawlor BA. What predicts persistent depression in older adults across Europe? Utility of clinical and neuropsychological predictors from the SHARE study. J Affect Disord. 2013;147:192-7.

65. Portellano-Ortiz C, Garre-Olmo J, Calvó-Perxas L, Conde-Sala $\mathrm{JL}$. Symptoms of depression and associated factors in persons aged 50 and over in Europe and Israel: analysis of data from the SHARE Project. Int J Geriatr Psychiatry. 2016;31: 1250-1.

66. World Health Organization. Preventing suicide: a global imperative. Geneva: WHO; 2014. Available from: http://apps.who. int/iris/bitstream/10665/131056/1/9789241564779_eng.pdf

67. Wu J, Värnik A, Tooding LM, Värnik P, Kasearu K. Suicide among older people in relation to their subjective and objective well-being in different European regions. Eur J Age. 2014;11: $131-40$. 